\title{
Long-Term Antihypertensive Effect of Angiotensin-Converting Enzyme Inhibitory Peptide LAP
}

\author{
Luo Ming Shen Yi Liu Chi Huan Zheng Zhanxia Li Yuqing Deng \\ Junlin Huang Lingxia Li Hong Fang \\ Department of Cardiology, Affiliated Tongji Hospital of Tongji University, Shanghai, PR China
}

\section{Key Words}

Antihypertensive $\cdot$ Angiotensin-converting enzyme •

Inhibitory peptide $\cdot$ LAP

\begin{abstract}
Objective: To study the antihypertensive effects of the angiotensin-converting enzyme (ACE)-inhibitory peptide LAP on blood pressure in spontaneously hypertensive rats (SHRs). Methods: A cohort of 12-week-old SHRs was randomly divided into 2 distinct groups, and ACE-inhibitory peptide LAP (experimental group) or physiological saline (controls) were administered. Caudal arterial blood pressure was then measured at specific time points (0, 4, 8 and 12 weeks). Results: Systolic blood pressure of the SHRs showed a significant decrease after intraperitoneal injection with the ACE-inhibitory peptide LAP. Moreover, this depressurization effect lasted for over 1 month. Conclusion: Systolic blood pressure of SHRs could effectively be depressed in the long term by antihypertensive activity mediated by the ACE-inhibitory peptide LAP.
\end{abstract}

Copyright $\odot 2011$ S. Karger AG, Base

\section{Introduction}

Long-term hypertension is the key risk factor for myocardial infarction, stroke and the development of heart failure, and it also seriously affects glycolipid metabolism and poses a potentially life-threatening risk. The incidence of hypertension has increased over recent decades. Although the molecular mechanism underlying hypertension remains to be elucidated, hypotensive drugs such as diuretics, $\beta$-receptor blockers, $\alpha_{1}$-receptor blockers, calcium antagonists, angiotensin-converting enzyme inhibitors (ACEI) and angiotensin II AT-1 receptor blockers - are currently being widely used to reduce blood pressure. The recently developed ACEI exhibits specific therapeutic activity to reduce hypertension.

The renin-angiotensin system is the most critical hormonal system for the regulation of cardiovascular physiological function. ACE is a zinc protease that plays a key role in the regulation of blood pressure by cleaving angiotensin I to angiotensin II and C-terminal bipeptide. As a widely used vasoconstrictor, angiotensin II plays a critical role in the etiology of hypertension. Thus, blood pressure could be effectively reduced by inhibiting ACE, resulting in improved cardiac remodeling. Therefore, widely used ACEI (e.g. captopril) represent a milestone in the development of cardiovascular drugs. Although chemically synthesized ACEI effectively reduces blood pressure, adverse effects (including cough, allergic reactions, taste disturbances and skin rashes) have been observed. Moreover, due to its short action time, long-term administration is required, which is difficult due to low levels of patient compliance. Various attempts in the field of biotechnology have been made to develop a form of ACE-

\section{KARGER}

Fax +4161306 1234 E-Mail karger@karger.ch www.karger.com

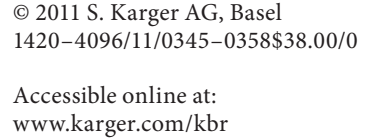

Hong Fang

Department of Cardiology

Tongji Hospital Affiliated to Tongji University

Shanghai 200065 (PR China)

Tel.+8602166111 529, E-Mail de_61@yahoo.com.cn 
inhibitory peptide which is improved with respect to safety, frequency of adverse effects and rate of absorption [1-8].

Since the ACE-inhibitory peptide was first discovered in Bothrops venom, more and more ACE-inhibitory peptides have been isolated from the enzymolytic production of proteins, including casein, lactalbumin, corn gluten protein, gelatin, plasma protein and chicken protein. This category comprises peptides from animal genera and botanic genera, including milk protein (casein, lactalbumin), fermented food, animal protein, vegetable protein and man-made ACE-inhibitory peptide $[1,2]$. According to the previous investigation of ACE-inhibitory peptide, the inhibitory activity of the inhibitory blood pressure peptide is strongly correlated with its amino acid sequence. Recent attempts to improve the activity of synthetic ACE-inhibitory peptide have included efforts to improve peptide activity, production stability, bioavailability and in vivo half-life. In the 1980s, widespread investigations of the inhibitory blood pressure peptide were performed to develop ways to reduce blood pressure. Several exhibited potential economic and social benefits.

Currently, the production of ACE-inhibitory peptide from food protein involves the use of microorganisms and enzymolysis. Nevertheless, large variations have been observed for different enzymatic cleavage sites. Moreover, the function of a particular peptide segment also exhibited a tendency to change over time. Therefore, more effective peptide synthesis is required. The solidphase synthesis polypeptide method was first developed by Merrifield [9] and paved the way for techniques that utilized chemistry, biochemistry, medicine, immunology and molecular microbiology. With the development of research on joint molecules, elimination methods and protecting groups, as well as new types of resin, the application of solid-phase methods in polypeptide synthesis became more widespread. Using this method, nearly all polypeptides could be produced at a high yield [10]. As ACE-inhibitory peptide is a short peptide with a low-molecular-weight, solid-phase synthesis after sequence analysis of the separated enzymolysis products represents an option that is more economical for full-scale production than direct separation and purification, as performed in enzymolytic production. The amino acid sequence of the hypotensive peptide suggests the feasibility of directly synthesizing the peptide after the natural version has been remodeled. Compared with traditional chemically synthesized hypotensive drugs, the great advantages of the hypotensive peptide are as follows: (1) improved safe- ty; (2) selective blood pressure depression. Lactoferrin (Lf), an iron-binding glycoprotein of the transferrin family, is present in many biological fluids including milk, saliva, tears, mucous fluid and blood. Lf consists of a single polypeptide chain with a molecular mass of about 80 $\mathrm{kDa}$, and it possesses two iron ion-binding sites per molecule [11]. Several physiological functions of Lf - including modulation of the inflammatory response, activation of the immune system and control of myelopoiesis - have been mentioned previously [12]. The antibacterial activity of lactoferricin was 400 times stronger than that of undigested Lf against Escherichia coli O-111 [13] and the effect of Lf on ACE activity has been confirmed [14]. Therefore, we employed the new peptide LAP, which was synthesized according to bovine Lf, and the effects of this new peptide upon blood pressure and remold were investigated in the present study.

\section{Methods}

Production of ACE-Inhibitory Peptide LAP

The ACE-inhibitory peptide LAP was synthesized according to the peptide sequence of the natural polypeptide. The peptide was synthesized by a Symphony 12-channel solid-phase peptide synthesizer using software version 201 (Applied Protein Technologies).

The synthesis procedures were as follows: (1) sufficient dimethylformamide and dichloromethane were added in accordance with the required amount of protected Freamine III, as calculated by the software; (2) $100 \mu$ mol FMOC-AA-Wang resin was then added to the reactor; (3) a 15-mg centrifuge tube was set on the pipe to collect the cutting solution; (4) the program parameters were set as follows: dissolution time was $30 \mathrm{~min}$, followed by deprotection twice for 5 and $15 \mathrm{~min}$, respectively, condensation for $30 \mathrm{~min}$ and dissection for $2 \mathrm{~h}$; (5) precipitation with ether as the dissection solution.

The synthetic peptides were purified using Shimadzu highperformance liquid chromatography (Shimadzu; and Class-VP software, Sevial System). The physical characteristics were as follows: white powder, moderate water solubility, purity above $95 \%$, and kept sealed at $-20^{\circ} \mathrm{C}$. Bovine serum albumin (BSA) was applied as the vector. The EDC method and ACE-inhibitory peptide were also used before dialysis. The product was stored at $-20^{\circ} \mathrm{C}$.

\section{Animals}

A cohort of 18 male SHRs weighing from 220 to $260 \mathrm{~g}$ were obtained from the Animal Center of the Second Medical College in Shanghai. All rats were housed in separate cages under a 12hour light/dark cycle with ad libitum access to food and water. Room temperature was kept around $25^{\circ} \mathrm{C}$, and humidity was $45-$ $50 \%$. This study was approved and performed according to the Guide for the Care and Use of Laboratory Animals of the National Institutes of Health, as well as the guidelines of the Animal Welfare Act. 
Experimental Grouping and Procedure

The experimental rats $(\mathrm{n}=18)$ were randomly divided into an experimental group $(n=9)$ and a blank control group $(n=9)$ after 1 week of adaptive breeding. LAP peptide was administered to the experimental group using intraperitoneal injection. Due to incomplete 1:1 binding between vector and polypeptide, $500 \mu \mathrm{g}$ LAP was injected 4 times (at 1, 3, 5 and 7 weeks) for each rat in the experimental group. The systolic pressure of rat tails and 30-second heart rate entrainment were detected using tail-covering methods at $0,4,8$ and 12 weeks, as previously reported [7]. Subsequently, the blood was obtained from the fossa orbitalis. After centrifugation $(3,000 \mathrm{rpm}$ for $10 \mathrm{~min})$, supernatant was obtained and stored at $-20^{\circ} \mathrm{C}$. Freund's complete adjuvant was applied here for the first time; note that other studies have used Freund's incomplete adjuvant. Similar injections of physiological saline solution were used as the positive control. After abdominal cavity anesthesia was induced with $10 \%$ chloral hydrate, the heart, doublestage mesenteric artery, kidney and liver were obtained, and then fixed by $10 \%$ neutral formalin, embedded in paraffin and subjected to HE staining. Finally, the sections were observed under light microscopy $(\times 100-400)$.The evaluation criteria of pathological change were $>1$ location of pathological change per field (lowlevel multifocal) and 1 location of pathological change per field (low-level focal).

\section{Enzyme-Linked Immunosorbent Assay}

After 5 rounds of immunization, $0.1 \mathrm{ml}$ standard preparation was added to each well of a 96-well microtiter plate (BD Biosciences). Wells were then coated with $50 \mathrm{ng} / \mathrm{ml}(100 \mu \mathrm{l} /$ well $)$ of purified human angiotensin antibody and incubated at $4^{\circ} \mathrm{C}$ overnight. The plate was blocked with $3 \%$ nonfat dry milk in PBS-T (PBS, $\mathrm{pH}=7.3,0.05 \%$ Tween-20) at room temperature for $2 \mathrm{~h}$. The sample was loaded at a 1:100 dilution in 3\% nonfat dry milk/PBS-T, followed by serial 5 -fold dilutions. After incubation at $37^{\circ} \mathrm{C}$ for $1 \mathrm{~h}$, the plate was washed with PBS-T, and incubated at $37^{\circ} \mathrm{C}$ for $2 \mathrm{~h}$ with a combination of 2 separate secondary antibodies at 100 $\mu \mathrm{l} /$ well: 1:5,000 dilution of HRP-conjugated goat anti-mouse IgG (Fc $\gamma$ fragment-specific), and a 1:5,000 dilution of HRP-conjugated AffiniPure goat anti-mouse $\operatorname{IgG}+\operatorname{IgM}(\mathrm{H}+\mathrm{L})$ (both from Jackson Immunology Research Laboratories). Antigen was detected by incubation with $100 \mu \mathrm{l} /$ well of tetramethylbenzidine for 15 min, and the reaction was stopped by $50 \mu \mathrm{l} /$ well of $1 \mathrm{M} \mathrm{HCl}$. The plate was read at $450 \mathrm{~nm}$ using an automated microplate reader (Bio-Tek Instruments). Screening of subsequent hybridomas was performed similarly, with HRP-conjugated goat anti-mouse IgG $+\operatorname{IgM}$ used as the secondary antibody. In addition, hybridoma screening included negative selection of clones that recognized an unrelated control His-tagged protein, as well as positive selection of clones recognizing a second recombinant angiotensin I/II without a His epitope tag. For cross-reactivity studies, wells were coated with either human or mouse fl-angiotensin, and human $\mathrm{N}$ - and C-terminal angiotensin fragments were used for epitope mapping. Unlabeled antibodies were incubated first, followed by reaction with the biotinylated antibodies to detect binding.

The absorbance measurement is directly proportional to the concentration of angiotensin (I or II). A standard curve was plotted using the concentration of standard preparation on the $\mathrm{x}$-axis and the ratio between the optical density value of the preparation (B) and the optical density value of the preparation at the zero point (B0) on the y-axis.
Table 1. Systolic pressures ( $\mathrm{mm} \mathrm{Hg}$ )

\begin{tabular}{lrr}
\hline & \multicolumn{1}{l}{ LAP } & \multicolumn{1}{c}{ Control } \\
\hline Week 0 & $185.33 \pm 6.39^{*}$ & $178.86 \pm 5.44$ \\
Week 12 & $154 \pm 11.75$ & $178.1 \pm 11.5$ \\
\hline
\end{tabular}

Data presented as means \pm SEM. ${ }^{*} \mathrm{p}<0.01$ vs. week 12 .

Blood Pressure Measurement

SHRs were fixed. The arteria caudalis from each rat was then heated. The mean value of systolic arterial pressure in rat tails was measured by 3 repeated measurements.

\section{Statistical Analysis}

Data are expressed as means \pm SEM. All data were analyzed by SPSS 10.0 software. Student's t test was used for before and after treatment comparisons. ANOVA was applied for the comparison of within-group variability. A p value of less than 0.05 was considered statistically significant.

\section{Results}

\section{Effect of LAP on Systolic Blood Pressure in SHRs}

The systolic blood pressure of SHRs in the experimental group began to drop 1 month after administration. In addition, this reduction was sustained until the end of the experiments. Moreover, the experimental group was significantly different from the blank control group - LAP produced a more marked antihypertensive effect at 12 weeks after injection and showed a longer decrease in systolic blood pressure (table 1).

\section{Levels of Angiotensin I and II in SHRs}

In our study, we found that levels of angiotensin I increased during the 8th week, but then dropped in the 12th week. In contrast, levels of angiotensin II decreased during the 8 th week and then showed significant recovery (fig. 1).

To measure the variability in levels of angiotensin, we compared serum angiotensin I in the experimental group and control group SHRs. The results showed no significant difference during week 0 ( $\mathrm{p}>0.05)$; however, during the 12th week, the 2 groups were significantly different $(p<0.001)$. Moreover, levels of angiotensin I in the control group during the 12th week were significantly increased in comparison to week 0 ( $p<0.001$; fig. 1$)$. While comparing the levels of angiotensin II in SHR serum between the experimental group and control group, we ob- 
Fig. 1. Variations in angiotensin I (a) and II (b) in the blood serum of SHRs.

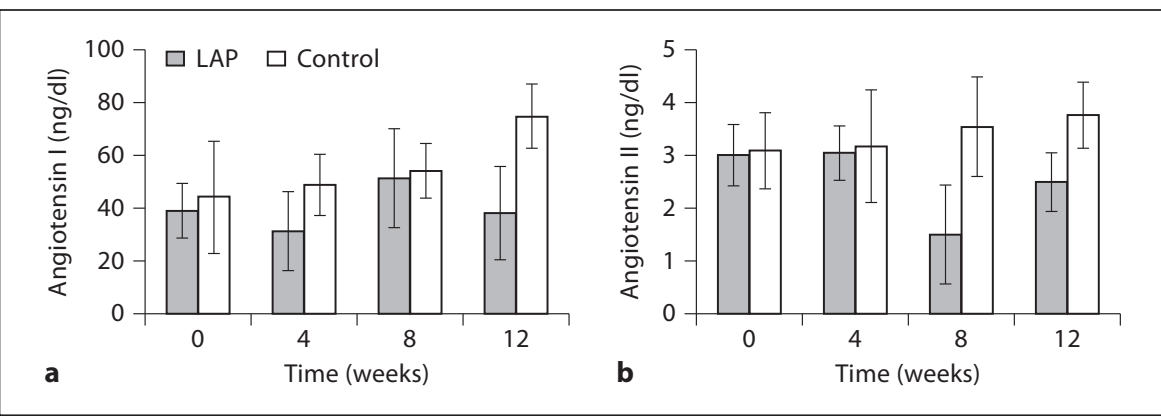

served that during week 0 the 2 groups were not significantly different $(\mathrm{p}>0.05)$. Nevertheless, during the 12th week, the 2 groups were significantly different $(\mathrm{p}<0.01)$. Furthermore, levels of Ang II in control groups during the 12th week also showed significant increases as compared with levels during week 0 ( $\mathrm{p}<0.05$; fig. 1$)$.

\section{Heart Rate Variability}

We compared variation among the 3 groups. The results showed that heart rate in the LAP group decreased in the 12th week $(p<0.001)$. However, heart rates in the control group changed little, with no significant difference from weeks 0 to $12(\mathrm{p}<0.01$; table 2$)$.

\section{Ratio of Heart and Body Weight to Thickness of \\ Double-Stage Mesenteric Artery Wall}

After calculating the ratio of heart and body weight in the 2 groups (means \pm SEM), we found a significant difference ( $\mathrm{p}<0.001)$ when comparing the experimental group $(0.00012 \pm 0.00004)$ and blank control group $(0.00441 \pm 0.00147)$. The greatest thickness of the double-stage mesenteric artery wall was observed in the blank control group $(6.8 \pm 1.7$ vs. $4.5 \pm 1.0 \mu \mathrm{m}, \mathrm{p}<0.01)$.

\section{Pathological Changes in the Main Target Organ}

In our study, the gross appearance of all SHRs was as follows: neither hematocele nor fluid were detected in the abdominal cavity; there were also no nodules or adhesions. Then under the fluorescent microscope, we observed that the experimental group exhibited the lowest levels of pathological change in main target organs, such as the heart, kidney, liver and double-stage mesenteric artery wall. Nevertheless, in the control group there were some pathological changes, such as low-level multifocal histiocytic myocarditis, low-level focal histiocytic myocarditis and intima sclerosis in the artery. Further, the renal glomerulus showed obvious atrophy. The lumens of efferent glomerular arterioles became stenotic (table 3).
Table 2. Variations in heart rate (bpm)

\begin{tabular}{lrl}
\hline & \multicolumn{1}{c}{ LAP } & Control \\
\hline Week 0 & $507 \pm 13.14^{* *}$ & $490.57 \pm 20.82^{*}$ \\
Week 12 & $487.67 \pm 23.67^{* *}$ & $503.86 \pm 24.42^{*}$ \\
\hline
\end{tabular}

Data presented as means \pm SEM. ${ }^{*} \mathrm{p}<0.05,{ }^{*} \mathrm{p}<0.01$ vs. week 12 .

Table 3. Histological findings

\begin{tabular}{llll}
\hline Organ & Histological findings & LAP & $\begin{array}{l}\text { Con- } \\
\text { trol }\end{array}$ \\
\hline Cerebrum & reduced neuron density & 1 & 4 \\
Heart & low-level multifocal histiocytic myocarditis & 1 & 3 \\
Heart & low-level focal histiocytic myocarditis & 0 & 3 \\
Heart & low-level focal myocardial fibrosis & 0 & 3 \\
Heart & focal swelling of the media in intramural arteries & 0 & 0 \\
Heart & intima sclerosis in vein or artery & 0 & 4 \\
Kidney & low-level multifocal inflammation & 1 & 0 \\
Kidney & low-level focal inflammation & 2 & 0 \\
Kidney & renal glomerulus: low-level multifocal atrophy & 1 & 3 \\
Kidney & renal glomerulus: low-level focal atrophy & 1 & 3 \\
Kidney & stenotic glomerular arterioles & 1 & 4 \\
Kidney & casts & 0 & 5 \\
\hline
\end{tabular}

\section{Discussion}

Currently, hypertension is a widespread health problem. Physicians are actively focusing on how to control hypertension, as well as how to prevent or attenuate the condition so as to improve the quality of life for each patient. Nowadays, multiple methods that take advantage of particular biochemical pathways are used to control hypertension. Synthetic antihypertensive drugs are used, owing to good curative effects and short half-life, although various adverse effects have reduced patient com- 
pliance. However, certain natural or synthesized peptides which play critical roles in the renin-angiotensin system were able to reduce blood pressure. In addition, bioactive peptides which inhibit angiotensin-I-converting enzyme in the cardiovascular system could contribute to the prevention and treatment of hypertension. Due to their safety and effectiveness, the novel ACE-inhibitory peptides (including LAP), which are regarded as competitive substrates for ACE, represent a new direction for the therapeutic treatment of hypertension $[15,18]$.

\section{Antihypertensive Effect and Half-Life of ACE-Inhibitory Peptides Were Determined by Protein Structure}

The function of an ACE-inhibitory peptide is correlated with its spatial structure. The structure is primarily determined by amino acid composition. The majority of peptides were competitive inhibitors, and the remainder were non-competitive inhibitors. For instance, Nakagomi et al. [19] obtained 2 types of ACE-inhibitory peptide from the separation of a trypsin enzymolysis solution of human plasma. These peptides were able to inhibit the activity of ACE and diminish the production of angiotensin II, and thus prevent elevations in blood pressure. Compared with angiotensin I and bradykinin, ACE-inhibitory peptides showed stronger affinity to the ACE activity region, thus inhibiting ACE catalysis and the hydrolysis of angiotensin I into angiotensin II. These peptides also catalyze the hydrolysis of bradykinin to yield deactivated fragments.

Current investigations of the correlation between ACE inhibitor activity and structure suggested that the structure responsible for the high activity of the antihypertensive peptide is either a Pro, Phe or Thy sequence in the C-terminal or another hydrophobic amino acid sequence. The inhibitory effect was the strongest when the N-terminal included an aromatic series amino acid or the Cterminal included Tyr, Try and Pro. The characteristics of peptides that inhibited ACE activity were as follows: (1) relatively low molecular weight, containing 2-12 amino acid residues, extending 1 bipeptide from the $\mathrm{N}$-terminal - the inhibitory activity of the corresponding tripeptide was usually enhanced initially and then eventually decreased; (2) the activity of a tripeptide or bipeptide containing Phe, Pro, Trp and Tyr in the C-terminal was higher; (3) the activity of a tri- or bipeptide within Val and Ile within the $\mathrm{C}$-terminal was higher - when the $\mathrm{N}$-terminal contained a Pro, the activity level decreased; (4) with Lys and Arg at C-terminal residues, the inhibitory activity of the peptide was improved. Carbamidine in the lateral chain of Lys or Arg or the positive charge of $\varepsilon$-amino also play a critical role. The replacement of an Arg residue in the C-terminal inhibited peptide function $[1,2,5,6,8$, 20]. We aimed to use these findings to improve the antihypertensive effect of the peptide, obtained using direct sold-phase synthesis. Systolic pressure of SHRs was significantly decreased, which confirmed our hypothesis.

The protein and polypeptide drugs are primarily eliminated in vivo through degradation, excretion and receptor-mediated internalization. Polypeptide agents with molecular weight less than $20 \mathrm{kDa}$ were filtered by glomerular filtration during the metabolic process. While passing through the renal tubule, the polypeptide agent was partially degraded by protease and eliminated from the urine. Consequently, the half-life is quite short. To maintain the therapeutic effect, a large dose and repeated administration were required. Frequent injections over a long-term period caused patient suffering, as well as other adverse side effects. The pharmacokinetics of the drug are affected by its chemical structure. In addition, a series of physico-chemical properties are determined by chemical structure, such as $\mathrm{PH}$ value, particle diameter and crystal form. These factors affect solubility, absorption, bioavailability and half-life. The structural modification of polypeptides could improve the pharmacokinetic activity of the drug. Recent research has elucidated the factors necessary to improve the metabolic stability of polypeptide drugs (including changes in biological half-life) through chemical modification, gene fusion, point mutation and preparation reconstruction. In addition, through the combination of chemical modification and genetic engineering, protein engineering might play a more important role.

In our study, solid-phase synthesis was used to synthesize the ACE-inhibitory peptide LAP. This technique was coupled with BSA. Then, peritoneal injection was performed to observe the effect on blood pressure in SHRs. The results indicated that systolic pressure of SHRs significantly decreased, and the antihypertensive effect could be sustained for more than 1 month. These results indicate that BSA, Freund's adjuvant and intraperitoneal injection were able to extend the half-life of LAP. We determined that macromolecular BSA coupling was able to prevent the degradation of LAP; however, excretion reduced the rate of LAP accretion. As previous studies have reported, Freund's adjuvant and intraperitoneal injection were able to reduce the rate of absorption of LAP [21, 22]. In addition, the antihypertensive effect of LAP may have been correlated with the immunological response. LAP may have provoked an immunological reaction in vivo as a type of biological agent. However, using the same methods, the change in systolic pressure using physiological 
saline showed no significant difference in the corresponding groups. The levels of angiotensin II in serum decreased as compared with the control group over the first 8 weeks, but then increased during the 12th week. Levels of angiotensin I increased over 8 weeks, but then decreased during the 12th week, which also suggested that LAP strongly affected ACE activity. In the 12th week, angiotensin II levels began to recover. Considering long-term inhibition of ACE activity, the chymase pathway might have been replaced by compensatory activity $[23,24]$.

\section{Cardiovascular Remodeling Mediated by \\ ACE-Inhibitory Peptide LAP}

The renin-angiotensin-aldosterone system (RAAS) is not only involved in the regulation of blood pressure, but also affects the cardiovascular reconstruction caused by long-term excessive hypertension. Ventricular vascular remodeling is a progressive process, which is mainly due to sustained adrenergic nervous excitation, the activation of RAAS and persistent release of body fluid cytokines, caused by metabolic activation of cardiac muscle. Activation of the RAAS system and heart is the critical mechanism of congestive heart failure. Each component of the RAAS plays a critical role in the cardiovascular system. Angiotensin II is the final mediator of the RAAS, mediating multiple functions of the circulatory, endocrine, autocrine and paracrine systems. As a circulating peptide, angiotensin II plays a key role in the effect of hemodynamics and blood volume in the cardiovascular system. Moreover, as a type of autocrine and paracrine peptide, local synthesized angiotensin II is involved in the regulation of hemodynamics, cell growth and reconstruction, and facilitates neurotransmitter release. During heart remodeling, especially without any evident congestive heart failure, RAAS activity is upregulated, and levels of end products such as angiotensin II are increased. Angiotensin II is a hormonelike substance that affects blood vessel contraction and stimulates the secretion of aldosterone, with additional effects on the thirst center of the hypothalamus that induce water-sodium retention and aggravate congestive heart failure. At the cellular level, angiotensin II was able to cause myocardial hypertrophy due to upregulation of the genes that code for the angiotensin II AT1 receptor in cardiac muscle cells and fibroblastic cells. Angiotensin II plays a critical role in the induction of cardiac hypertrophy, as well as molecular, biochemical and mechanical aspects of the cardiovascular remodeling pathway. These cellular changes suggest that the peptide could be improved to limit cell hypertrophy, necrosis, apoptosis, fibrosis, fibroid collagen and fibroblast proliferation [25-40].
Animal experiments have verified that chemically synthesized ACEI could significantly inhibit this effect [41]. However, the toxic side effects of the inhibitor become obvious when the dose is increased. In our investigation, the heart weight was lower in the experimental group as compared to the control group. The heart rate in the experimental group also decreased significantly. We preliminarily confirmed that LAP not only improved structural reconstitution, but also affected electric reconstruction. Changes in the double-stage arteria mesenterica wall indicated that LAP was also able to affect vascular remodeling. In theory, the half-life of ACE-inhibitory peptide LAP is long. While ventricular remodeling is a progressive process, the characteristics of the ACE-inhibiting peptide LAP inhibit ventricular remodeling. Meanwhile, gross anatomy and light microscope observation revealed that the pathological change in LAP was quite slight, which indicated that the toxic side effects were quite limited.

\section{Limitations of the Experiment}

To emphasize that our research on ACE-inhibitory peptide is a preliminary study, certain aspects of drug pharmacokinetics, effect time, half-life and the dose/response relationship remain unclear. We have not yet investigated the chymase route and bradykinin pathway in relation to angiotensin I-VII. The direct evidence on the effect of the chymase route that is currently available is still insufficient. In addition, the effect of ANG on LAP is also not clear. Currently, we are focusing on characterizing the peptide's pharmacological profile.

\section{Conclusion}

Our evidence indicated that the ACE-inhibiting peptide LAP exerts an antihypertensive effect. This effect could be sustained for more than 1 month. However, the long-term antihypertensive mechanism remains to be elucidated. It may be correlated with the rate of peptide hydrolysis, which is delayed by the immunological response induced by treatment with BSA/Freund's adjuvant. LAP is not only used to control blood pressure, but also to improve the reconstruction of heart and vessels in order to alleviate the damage due to hypertension. Pathological examination preliminarily confirmed treatment with this peptide did not cause any serious side effects in SHRs. Intraperitoneal injection is the most safe and effective route of administration. In conclusion, the ACEinhibiting peptide LAP is a hypotensive drug with potential for clinical applications. 


\section{References}

$>_{1}$ Hong F, Ming L, Yi S, Zhanxia L, Yongquan W, Chi L: The antihypertensive effect of peptides: a novel alternative to drugs? Peptides 2008;29:1062-1071.

2 Pandey R, Quan WY, Hong F, Jie SL: Vaccine for hypertension: modulating the reninangiotensin system. Int J Cardiol 2009;134: $160-168$.

-3 Byers LD, Wolfenden R: Binding of the byproduct analog benzylsuccinic acid by carboxypeptidase A. Biochemistry 1973;12: 2070-2078.

4 Case DB, Atlas SA, Laragh JH, Sealey JE, Sullivan PA, Mckinstry DN: Clinical experience with blockade of the renin-angiotensin-aldosterone system by an oral converting-enzyme inhibitor (captopril) in hypertensive patients. Prog Cardiovasc Dis 1978;21:195206

5 Jaspard E, Costerousse O, Wei L, Corvol P, Alhenc-Gelas F: The angiotensin I-converting enzyme (kininase II): molecular and regulatory aspects. Agents Actions 1992;38(suppl):349-358.

6 Dézsi L: Fibrinolytic actions of ACE inhibitors: a significant plus beyond antihypertensive therapeutic effects. Cardiovasc Res 2000;47:642-644.

7 Murray BA, FitzGerald RJ: Angiotensin converting enzyme inhibitory peptides derived from food proteins: biochemistry, bioactivity and production. Curr Pharm Des 2007;13: 773-791.

8 Vermeirssen V, Van Camp J, Verstraete W: Bioavailability of angiotensin I converting enzyme inhibitory peptides. Br J Nutrition 2004;92:357-366.

$\checkmark 9$ Merrifield RB, Vizioli LD, Boman HG: Synthesis of the antibacterial peptide cecropin A (1-33). Biochemistry 1982;21:5020-5031.

10 Galanis AS, Spyroulias GA, Pairas G, et al: Solid-phase synthesis and conformational properties of angiotensin converting enzyme catalytic-site peptides: the basis for a structural study on the enzyme-substrate interaction. Biopolymers 2004;76:512-526.

-11 Anderson KR, Sutton MG, Lie JT: Histopathological types of cardiac fibrosis in myocardial disease. J Pathol 1978;128:79-85.

12 Brock JH: The physiology of lactoferrin. Biochem Cell Biol 2002;80:1-6.

13 Bellamy W, Mitsunori T, Yamauchi K, Wakabayashi H, Kawase K, Tomita M: Identification of the bactericidal domain of lactoferrin. Biochim Biophys Acta 1992;1121:130136.

14 Lee NY, Cheng JT, Enomoto T, Nakamura I: The antihypertensive activity of angiotensin-converting enzyme inhibitory peptide containing in bovine lactoferrin. Chin J Physiol $2006 ; 49: 67-73$.
15 Nakamura Y, Masuda O, Takano T: Decrease of tissue angiotensin I-converting enzyme activity upon feeding sour milk in spontaneously hypertensive rats. Biosci Biotechnol Biochem 1996;60:488-489.

16 Suetsuna K, Chen JR: Identification of antihypertensive peptides from peptic digest of two microalgae, Chorella vulgaris and Spirulina platensis. Mar Biotechnol (NY) 2001;3: 305-309.

17 Ondetti MA, Cushman DW: Enzymes of the renin-angiotensin system and their inhibitors. Annu Rev Biochem 1982;51:283-308.

18 Ma MS, Bae IY, Lee HG, Yang CB: Purification and identification of angiotensin I-converting enzyme inhibitory peptide from buckwheat (Fagopyrum esculentum Moench). Food Chen 2006;96:36-42.

19 Nakagomi K, Ebisu H, Sadakane Y, Fujii N, Akizawa T, Tanimura T: Properties and human origin of two angiotensin-I-converting enzyme inhibitory peptides isolated from tryptic hydrolysate of human serum albumin. Biol Pharm Bull 2000;23:879-883.

20 Nai-Yuan L, Juei-Tang C, Toshiki E, Ichiro N The antihypertensive activity of angiotensin- converting enzyme inhibitory peptide containing in bovine lactoferrin. Chin J Physiol 2006;49:67-73.

21 Mallikarjun Gouda KG, Gowda LR, Rao AG Rao AG, Prakash V: Angiotensin I-converting enzyme inhibitory peptide derived from glycinin, the 11S globulin of soybean (Glycine max). J Agric Food Chem 2006;54: 4568-4573.

22 Motoi H, Kodama T: Isolation and characterization of angiotensin I-converting enzyme inhibitory peptides from wheat gliadin hydrolysate. Nahrung 2003;47:354-358.

23 Urata H: Pathological involvement of chymase-dependent angiotensin II formation in the development of cardiovascular disease. J Renin Angiotensin Aldosterone Syst 2000; 1:S35-S37.

-24 Li M, Liu K, Michalicek J, Angus JA, Hunt JE, Dell'Italia LJ, Feneley MP, Graham RM, Husain A: Involvement of chymase-mediated angiotensin II generation in blood pressure regulation. J Clin Invest 2004;114:112-120.

25 Wollert KC, Drexler H: The renin-angiotensin system and experimental heart failure. Cardiovasc Res 1999;43:838-849.

26 Lijnen P, Petrov V: Renin-angiotensin system, hypertrophy and gene expression in cardiac myocytes. J Mol Cell Cardiol 1999; 31:949-970.

27 Weber KT, Brilla CG: Pathological hypertrophy and the cardiac interstitium: fibrosis and the renin-angiotensin-aldosterone system. Circulation 1991;83:1849-1865.
28 Tan LB, Jalil JE, Pick R, Janicki JS, Weber KT: Cardiac myocyte necrosis induced by angiotensin II. Circ Res 1991;69:1185-1195.

29 Sharov VG, Sabbah HN, Shimoyama H, Goussev AV, Lesch M, Goldstein S: Evidence of cardiocyte apoptosis in myocardium of dogs with chronic heart failure. Am J Pathol 1996;148:141-149.

-30 Teiger E, Dam TV, Richard L, et al: Apoptosis in pressure overload-induced heart hypertrophy in the rat. J Clin Invest 1996;97:28912897.

-31 Olivetti G, Abbi R, Quaini F, Kajstura J, Cheng W, Nitahara JA: Apoptosis in the failing human heart. N Engl J Med 1997;336: 1131-1141.

- 32 Weber KT, Pick R, Silver MA, Moe GW, Janicki JS, Zucker IH: Fibrillar collagen and remodeling of dilated canine left ventricle. Circulation 1990;82:1387-1401.

33 Villareal FJ, Kim NN, Ungab GD, Printz MP, Dillmann WH: Identification of functional angiotensin II receptors on rat cardiac fibroblasts. Circulation 1993;88:2849-2861.

-34 Reiss K, Capasso JM, Huang HE, Meggs LG, Li PI, Anversa P: ANG II receptors, c-myc and c-jun in myocytes after myocardial infarction and ventricular failure. Am J Physiol 1993;264;H760-H769.

35 Sadoshima J, Izumo S: Molecular characterization of angiotensin II-induced hypertrophy of cardiac myocytes and hyperplasia of cardiac fibroblasts: critical role of the AT1 receptor subtype. Circ Res 1993;73:413-423.

36 Everett AD, Tufro-McReddie A, Fisher A, Gomez RA: Angiotensin receptor regulates cardiac hypertrophy and transforming growth factor-beta 1 expression. Hypertension 1994;23:587-592.

37 Sadoshima J, Xu Y, Slayter HS, et al: Autocrine release of angiotensin II mediates stretch-induced hypertrophy of cardiac myocytes in vivo. Cell 1993;75:977-984.

- 38 Ollivier JP, Bouchet VA: Prospects for cardioreparation. Am J Cardiol 1992;70:27C36C.

39 Brilla CG, Zhou G, Matsubara L, Weber KT: Collagen metabolism in cultured adult rat cardiac fibroblasts: response to angiotensin II and aldosterone. J Mol Cell Immunol 1994: 26:809-820.

40 Sheehan JP, Seelig MS: Interactions of magnesium and potassium in the pathogenesis of cardiovascular disease: magnesium cardiovascular disease. Magnesium 1984;3:301314.

41 Mann DL, Bristow MR: Mechanisms and models in heart failure: the biomechanical model and beyond. Circulation 2005;111: 2837-2849. 